\title{
Modeling of Kinetics of Mass-Exchange Processes for Fruit and Berry Production Preservation
}

\author{
Bazarnova Yu.G., Kuznetsova T.A., Aronova E.B. \\ Higher School of Biotechnology and Food Technology \\ Peter the Great St. Petersburg Polytechnic University, \\ St.Petersburg, Russia \\ j.bazarnowa2012@yandex.ru
}

\begin{abstract}
At preservation of fruits and berries mass-exchange processes take place in liquid mediums, which define quality of the canned production. The composition of covering syrup should guarantee preservation of turgor, taste and color of fruits and berries and prevent fermentation processes. We carried out construction and adequacy examination of kinetic model for moisture osmotic transfer for fruit-berry material to covering syrups at thermal and refrigerating preservation. We obtained empirical coefficients. It was established that moisture migration rate depends on berry type and syrup concentration. Moisture loss for more than $30 \%$ results in berries turgor loss, which makes its further storage impractical. Using the obtained equation and empirical constants, we have established that the duration of the refrigeration storage of cowberry canned in $30 \%$ sugar syrups for the stated conditions was about 130 days.
\end{abstract}

Keywords- kinetics modeling, mass-exchange processes, osmotic moisture transport, berries, syrup, preservation

\section{INTRODUCTION}

The most common cause of deterioration in the texture of food products during refrigeration processing and storage is a change in its moisture content, including loss of moisture, an increase in humidity, or migration of moisture. Moisture migration can occur in multicomponent products if individual components are characterized by different indicators of water activity $[1,2]$. The organoleptic perception of the product is governed by a combination of many changing factors. However, the correlation of organoleptic, physico-chemical and biochemical parameters is often absent. Testing the product during storage allows one to determine the indicators which are most important for assessing its quality and safety [3, 4].

The processes of diffusive transfer of soluble components and osmotic transfer of moisture limit the period of cold storage of canned fruits and berries in liquid media. The study of the kinetics of mass transfer processes leading to the redistribution of soluble substances in the "berries-syrup" system is relevant in the development of technologies based on fruit and berry raw materials preserved in liquid media.

For implementation of defrosting end storage of wild fruits and berries in liquid mediums in unregulated conditions the composition of covering syrups should guarantee quality (turgor, taste, color) of the fruits and berries and prevent fermentation processes $[5,7]$. The intensity of the diffusion- osmotic processes depends on a number of factors, including temperature, viscosity and density of the medium, the presence of various electrolytes. Therefore, when defrosting fruits and berries in liquid media, it is necessary to take into account the rheological properties of these media, the viscosity and density of which have a significant effect on the rate of diffusion of soluble substances.

With respect to berries cell juice the sugar-covering syrups are hypertonic solutions. In order to prevent plasmolysis, one should choose its concentrations in such a way as to ensure alignment of the osmotic pressures. From the other side, osmotic pressure should be enough for microorganism cell dewatering, its plasmolysis and total inactivation [8,9].

To assess the intensity of changes occurring in products during storage, and to obtain information about the influence of various factors on the storage time, the principles of modeling are used [10-12].

The development of kinetic models suitable for practical use has some difficulties. Most often, they are developed on the basis of empirical data obtained from model experiments. In this case, the necessary condition is to check the adequacy of the obtained models to prove that they are reliable not only in laboratory conditions, but also when describing real food systems [13].

The aims of the present work are to construct kinetic model of moisture osmotic transport process from the fruit-berry material to the covering syrups; carry out adequacy examination of the obtained model; obtain kinetic constants for various types of fruits and berries.

\section{MATERIALS AND METHODS}

In order to examine the adequacy of the developed mathematical model we used fresh and frozen cranberries and cowberries and syrups with sucrose content of 30,40 and $50 \%$. Analysis of sucrose content in berries and syrups was carried out by refractometry technique, which is widely used in many research areas [14-16].

\section{RESULTS AND DISCUSSION}

\section{A. Construction of physical-mathematical model}

For construction of appropriate physical-mathematical model we will consider the following terms: 
$V$ is juice volume in a berry, $\mathrm{m}^{3}$;

$v$ is total content of solvable sugars in a berry, mole;

$\tau$ is time of berry storage in syrup;

$C_{\mathrm{s}}$ is sucrose concentration in a syrup, mole $/ \mathrm{m}^{3}$.

$\mathrm{C}_{0}$ is total sugar concentration in a berry, mole $/ \mathrm{m}^{3}$, which might be presented as:

$$
C_{0}=\frac{v}{V}
$$

at this $\mathrm{C}_{0}<\mathrm{C}_{\mathrm{s}}$.

Due to appearance of osmotic pressure the water molecules from berry will migrate to the syrup through the berry surface layer. This layer is a membrane, which is permeable for water molecules and non- permeable for larger particles, in particularly, sucrose molecules. This process will continue until the sugar concentrations in a berry juice $C(\tau)$ and syrup $C_{s}$ become equal.

The osmotic water transport through the surface layer of a berry is a slow (and, consequently, laminar) flow of viscous liquid through small channels. So we may use the Poiseuille [17] formula for liquid volume $d V$, passing during the time $d \tau$, i.e. the following expression (2):

$$
-d V=\frac{p_{o} \cdot N \cdot S^{2} \cdot \xi}{\mu \cdot d} d \tau,
$$

where:

$\mathrm{p}_{0}$ is osmotic pressure, $\mathrm{Pa}$;

$\mathrm{N}$ is amount of channels in a berry surface layer;

$\mathrm{S}$ is sectional area of one channel, $\mathrm{m}^{2}$;

$\mathrm{d}$ is channel length which is equal to a berry surface layer width, m;

$\mu$ is dynamic water viscosity, $\mathrm{kg} /(\mathrm{m} \cdot \mathrm{s})$;

$\xi$ is dimensionless coefficient, which depends on the channel shape (for a round channel $\xi=1 / 8 \pi$ ).

Osmotic pressure is described by expression (3):

$$
p_{0}=\left(C_{s}-C(\tau)\right) R T \text {, }
$$

where:

$\mathrm{R}$ is universal gas constant, $\mathrm{J} /($ mole $\cdot \mathrm{K})$;

$\mathrm{T}$ is absolute temperature, $\mathrm{K}$.

By substituting (3) in (2) taking into account the following expressions:

$$
V=\frac{v}{C} ; \quad-d V=\frac{v \cdot d C}{C^{2}} .
$$

Let us obtain the following expression:

$$
\frac{C_{s}^{2} d C}{C^{2}}=k\left(C_{s}-C\right) d \tau ; \quad k=\frac{C_{s}^{2} \cdot N \cdot S^{2} \cdot \xi \cdot R \cdot T}{v \cdot \mu \cdot d} .
$$

The expression (5) is easy to integrate. Its solution, which meets the initial condition $\mathrm{C}(0)=\mathrm{C}_{0}$ is the following (6):

$$
\ln \left\{\frac{C\left(C_{s}-C_{0}\right)}{C_{0}\left(C_{s}-C\right)}\right\}-\frac{C_{s}}{C}+\frac{C_{s}}{C_{0}}=k \tau .
$$

Further we introduce dimensionless constants:

$$
\begin{gathered}
a=\frac{C_{0}}{C_{s}} ; \\
w=\frac{V}{V_{0}},
\end{gathered}
$$

where: $\mathrm{V}_{0}, \mathrm{~V}$ are initial and current moisture volume in a berry, $\mathrm{m} 3$;

And the expression (6) can be represented in the following way (8):

$$
\ln \left\{\frac{1-a}{w-a}\right\}+\frac{1-w}{a}=k \tau
$$

Fig.1 presents relations between dimensionless concentration $\mathrm{C} / \mathrm{C}_{\mathrm{s}}$ and dimensionless time $\mathrm{k} \tau$.

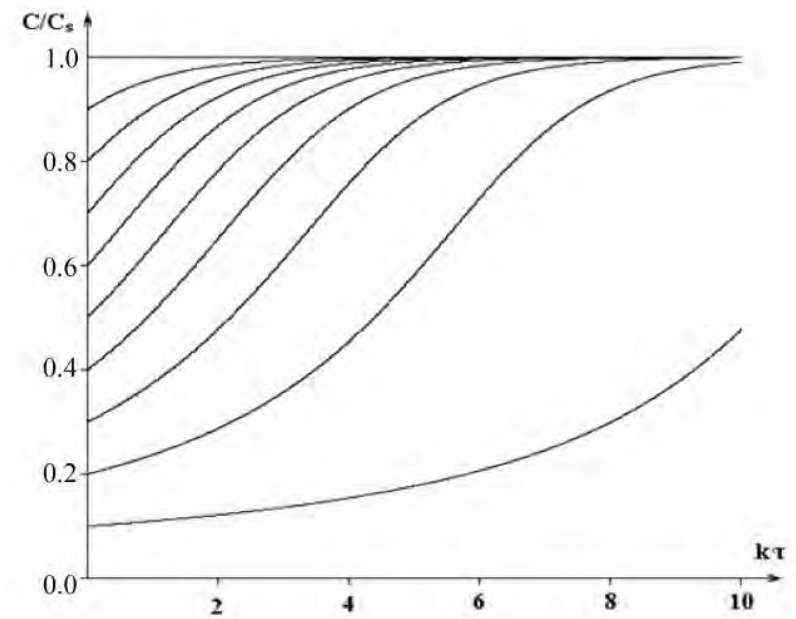

Fig. 1. Relation between dimensionless concentration of sugar in a berry $\mathrm{C} / \mathrm{C}$ and dimensionless time $\mathrm{k} \tau$ for various numerical values of dimensionless initial concentration $\mathrm{a}=\mathrm{C}_{0} / \mathrm{C}$

Empirical values of kinetic coefficient $\mathrm{k}$, obtained using the expression (8) are presented in Table 1.

TABLE I. CONSTANTS OF MOISTURE OSMOTIC TRANSPORT RATE, K, DAYS $^{-1}$ AT REFRIGERATORY STORAGE IN SYRUPS FOR CANNED CRANBERRIES AND COWBERRIES; $(4 \pm 2){ }^{\circ} \mathrm{C}$

\begin{tabular}{|l|l|l|l|}
\hline \multirow{2}{*}{ Name } & \multicolumn{3}{|l|}{$\begin{array}{l}\text { k values at various sucrose content in } \\
\text { syrups, days }\end{array}$} \\
\cline { 2 - 4 } & $30 \%$ & $40 \%$ & $50 \%$ \\
\hline Cowberry & $1.03 \cdot 10^{-2}$ & $1.16 \cdot 10^{-2}$ & $1.42 \cdot 10^{-2}$ \\
\hline Cranberry & $2.52 \cdot 10^{-2}$ & $2.75 \cdot 10^{-2}$ & $2.90 \cdot 10^{-2}$ \\
\hline
\end{tabular}

Fig. 2 presents research data on residual moisture content in canned (a) and unfrozen in syrups (b) cowberries depending on its storage duration at temperature of $(4 \pm 2)^{\circ} \mathrm{C}$.

It was established that turgor conservation for berries canned in syrups is reached at usage of sucrose concentration not more than $30 \%$. It allows one to reduce osmotic losses of the cell juice for canned and unfrozen in syrups berries. 


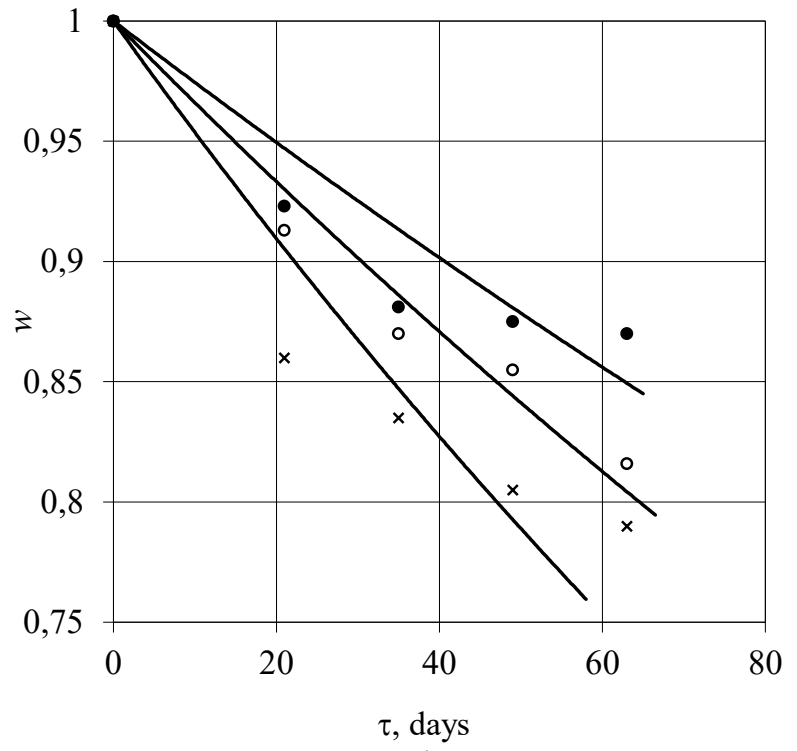

a)

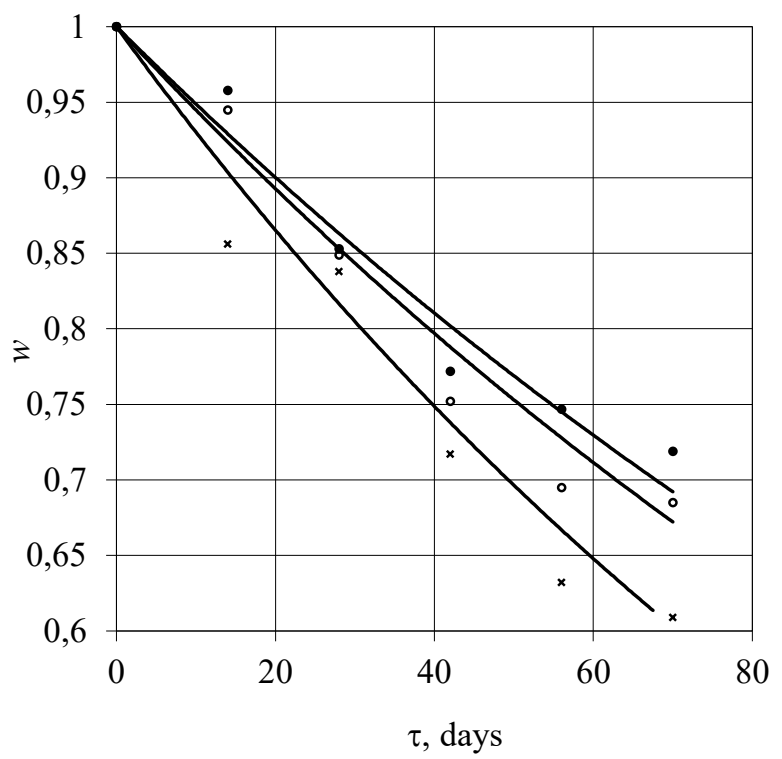

b)

Fig. 2. Relation between residual moisture content for canned (a) and unfrozen in syrups (b) cowberries and storage duration. $(4 \pm 2){ }^{\circ} \mathrm{C}$. Empirical data is shown by dots, lines stand for calculation data.

At berries preservation in isotonic syrups the osmotic concentration of berries cell juice is reaching the concentration of solvable dry syrup substances. So according to the expression (7) $a=\frac{C_{0}}{C_{s}} \rightarrow 1$, the formula (8) can be rewritten as:

$$
w=1-k \tau \text {. }
$$

\section{CONCLUSIONS}

The obtained expressions (6) and (8) might be used for development of composition of sugar-covering syrups and regulation of storage modes of preserved in covering syrups berries. They allow one to determine the residual moisture content in berries at any storage period [18].

It was established that moisture migration rate depends on berry type and syrup concentration. Moisture loss for more than $30 \%$ results in berries turgor loss, which makes its further storage impractical.

Using the expression (8) and empirical constants (Table 1), we have established that the duration of the refrigerator storage of cowberry canned in $30 \%$ sugar syrups for the stated conditions was about 130 days. During this period cowberries preserve its taste and turgor.

\section{References}

[1] G. Balasubrahmanyam, A. K. Datta, "Prevention of moisture migration in fondant coated biscuit", J. of food engineering, vol. 21 (2), pp. 235-244, 1994.

[2] T. P. Labusa, D. Riboh, "Theory and applications of Arrhenius kinetics to the prediction of nutrient losses in food", Food technology, vol. 36, pp. 56-61, 1982.

[3] Yu.G. Bazarnova, "Study of content of some food supplements with antioxidant activity in wild herbs and berries", Voprosy Pitaniia, vol. 76, №1, pp. 22-26, 2007.

[4] Yu. G. Bazarnova, Food shelf life: calculation and testing (translated. from English, ed. R. Stele), St. Peterburg: Professiya, 2006, 460 p.

[5] Yu. G. Bazarnova, T V. Shkotova, "The method for canning of wild berries” Pat. № 2286674 RF, MPK A23V 7/08, № 2004136398; of 10.11.06, 2006.

[6] G. Skrede, R. E. Wrolstad, P. Lea and G. Enersen, "Color Stability of Strawberry and Blackcurrant Syrups”, J. Food Sci., vol. 57, pp. 172-7, 1992.

[7] M. J. Beker, J. E. Blumbergs, E. J. Ventina and A. I. Rapoport, "Characteristics of cellular membranes at rehydration of dehydrated yeast Saccharomyces cerevisiae", Appl. Microbiol. Biotechnol., vol. 19, pp. 347-52, 1984

[8] M. J. Beker, A. J. Rapoport, P. B. Zikmanis and B.E. Damberga, "Dehydration as a yeast metabolism regulating factor", Environmental Regulation of Microbial Metabolism: Proceedings of the Federation of European Microbiological Societies Symposium Held in Pushchino, USSR, pp 105-11, 1985.

[9] N. M. Panagiotou, V. T. Karathanos and Z. B. Maroulis, "Effect of osmotic agent on osmotic dehydration of fruits", Dry. Technol., vol. 17, pp. 175-89, 1999.

[10] J. Kristott, "Fats and oils" in The stability and shelf-life of food. D. Kilcast, P. Subramaniam, Eds. Boca Raton, FL: CRC Press, Woodhead Publishing, 2000, P. 279-309.

[11] T. P. Labusa, M. K. Schmidt, "Accelerated shelf-life testing of food", Food Technology, vol. 39, pp. 57-62, 1985.

[12] Shelf-life of food - guide-lines for its determination and prediction. Institute of food science and technology (UK). London: IFST, 1993, 230 p.

[13] Yu. G. Bazarnova, T. E. Burova, A. L. Ishevsky, V. M. Zyukanov, "Possibilities of applying the principles of chemical kinetics to assess the quality of food products", Storage and processing of agricultural raw materials, vol.11, pp. 33-36, 2004.

[14] E.S, Lur'e, A.I. Sharov Technological control of raw material at candy production. Moscow: Kolos, 2001.

[15] A. V. Belashov, A. A. Zhikhoreva, V. G. Bespalov, V. I. Novik, N. T. Zhilinskaya, I. V. Semenova, O. S. Vasyutinskii, "Refractive index 
distributions in dehydrated cells of human oral cavity epithelium", J. Opt. Soc. Am. B Opt. Phys., vol. 34, pp. 2538-43, 2017.

[16] K. N. Semenov, G. O. Iurev, N. M. Ivanova, V. N. Postnov, V. V. Sharoyko, I. V. Prikhodko, I. V. Murin, "Physico-chemical properties of the C60-L-lysine water solutions" J. Mol. Liq., vol. 225, pp. 767-77, 2017.
[17] S. P. Sutera and R. Skalak, "The History of Poiseuille's Law", Annu. Rev. Fluid Mech., vol. 25, pp. 1-20, 1993.

[18] Yu. G. Bazarnova, V. E. Kucakova and S. V. Frolov, "Modeling of osmotic processes at berries storage in a syrup", Pishchevye tekhnologii2006: Proceedings of the Second International Scientific Conference, p. 14, 2006, October [17-19 October 2006, Odessa]. 